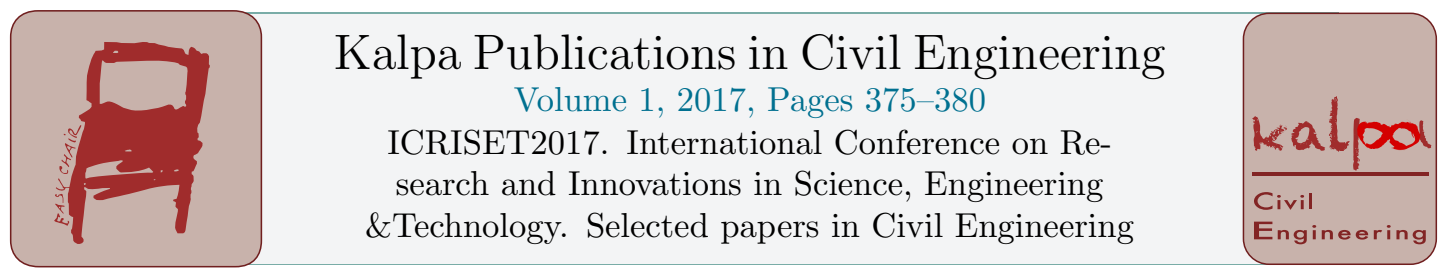

\title{
Seismic Performance Evaluation of RCC Buildings with Different Structural Configurations
}

\author{
Mohit K. Parmar ${ }^{1}$, Snehal V. Mevada ${ }^{2}$, Vishal B. Patel ${ }^{3}$ \\ Structural Engineering Dept., BVM Engineering College, Vallabh Vidhyanagar, India ${ }^{1}$ \\ Structural Engineering Dept., BVM Engineering College, Vallabh Vidhyanagar, India ${ }^{2}$ \\ Structural Engineering Dept., BVM Engineering College, Vallabh Vidhyanagar, India ${ }^{3}$
}

\begin{abstract}
This paper explores the comparative study of building performances at its performance points with two different response reduction factors. RCC Building with Bare Frame, RCC Building with Shear Wall and RCC Building with Stiffness Asymmetry, these three types of buildings are used for obtaining better objective of the study. Pushover Analysis is performed in SAP2000 to get performance of the building.
\end{abstract}

\section{INTRODUCTION}

Amongst the natural hazards, earthquakes have the potential for causing the greatest damages. Since earthquake forces are random in nature \& unpredictable, the engineering tools need to be sharpened for analyzing structures under the action of these forces. Pushover analysis which is an iterative procedure is used to get the performance point of the building which gives the lateral load carrying capacity of building and also provides information of hinges in building which declares the performance objective.

Pushover analysis is an approximate analysis method in which the structure is subjected to monotonically increasing lateral forces with an invariant height-wise distribution until a target displacement is reached. Pushover analysis consists of a series of sequential elastic analysis, superimposed to approximate a force-displacement curve of the overall structure. A two or three dimensional model which includes bilinear or trilinear load-deformation diagrams of all lateral force resisting elements is first created and gravity loads are applied initially. A predefined lateral load pattern which is distributed along the building height is then applied. The lateral forces are increased until some members yield. The structural model is modified to account for the reduced stiffness of yielded members and lateral forces are again increased until additional members yield. The process is continued until a control displacement at the top of building reaches a certain level of deformation or structure becomes unstable. The roof displacement is plotted with base shear to get the global capacity 
curve. These capacity curve is compared with demand curve and the intersection of both the curves is the Performance Point. By performance point, result will shows the hinges of building in each performance levels. From that result performance objective will be obtained and by changing the design it is possible to set performance objective of any building and that design is called a Performance Based Design (PBD).

In last decade, many researchers had focused on the application of the performance based design. Jose et al., ${ }^{[\mathrm{A}]}$ has analyzed the finite element models with various complexity are used in different types of analysis using linear-static, multi-mode pushover, and non-linear dynamic analysis. In conclusion, performance based seismic design is common in local structural engineering practice, as well as in the awareness of the real estate developers in the Philippines. Dubal et al., ${ }^{[\mathrm{H}]}$ deals with application of Performance based seismic design method for soft storey RC building frames (10 storeys). Push over analysis results show significance of PBSD method in frames having soft story at lower floor level compared to higher ones. And concluded that performance point of the frames (vertical irregularity of soft storey) designed by performance based seismic design (PBSD) method is enhanced than for all frames designed by conventional method.

Based on the brief literature review presented here, it is observed that comparison of performance of building by changing response reduction factor is not done yet. The objectives of the present study have been identified as follows:

- To carry out the performance based analysis to obtain performance levels of buildings for the future earthquake and also to understand its collapse mechanism in case of extensive damage.

- To obtain performance of building by changing response reduction factor in different types of buildings.

\section{NUMERICAL STUDY}

In Software SAP2000, Nonlinear is utilized to create 3D models and run all analyses using FEMA 356 and ATC 40. The software is able to predict the geometric nonlinear behaviour of space frames under static or dynamic loadings, taking into account both geometric nonlinearity and material inelasticity. Three models have been analysed by using two response reduction factor which are 5 and 3, (1) RCC building with bare frame (2) RCC building with full shear wall (3) RCC building with stiffness asymmetry.

Plan dimension of structure: 15 x $15 \mathrm{~m}$

$>$ Nos. of bays in X-direction: 3

$>$ Nos. of bays in Y-direction: 3

Floor height: $3.5 \mathrm{~m}$

$>$ Slab thickness: $120 \mathrm{~mm}$

$>$ Size of columns:

○ CASE $1,2=350 \times 350 \mathrm{~mm}$

○ CASE $3,4=450 \times 450 \mathrm{~mm}$

○ CASE 5, $6=500 \times 500 \mathrm{~mm}$

$>$ Floor finish load: $1 \mathrm{kN} / \mathrm{m} 2$

$>$ Zone: $\mathrm{V}$
$>$ Size of beams:

$$
\begin{array}{ll}
\circ & \text { CASE } 1,2=230 \times 460 \mathrm{~mm} \\
\circ & \text { CASE } 3,4=230 \times 460 \mathrm{~mm} \\
\circ & \text { CASE } 5,6=350 \times 550 \mathrm{~mm}
\end{array}
$$

$>$ Thickness of masonry wall:

$$
\begin{array}{cl}
\circ & \text { EXTERNAL }=230 \mathrm{~mm} \\
\circ & \text { INTERNAL }=115 \mathrm{~mm}
\end{array}
$$

$>$ Live load: $3 \mathrm{kN} / \mathrm{m} 2$

$>$ Seismic code: IS 1893 (Part 1) 2002

$>$ Design code: IS 456:2000

$>$ Response reduction factor: 
$\circ \quad$ Ordinary RC moment-resisting force $(\mathrm{OMRF})=3$ $\circ \quad$ Special RC moment-resisting force $(\mathrm{SMRF})=5$

\section{I. $\quad$ RCC Building with Bare Frame $(\mathrm{R}=5)$}

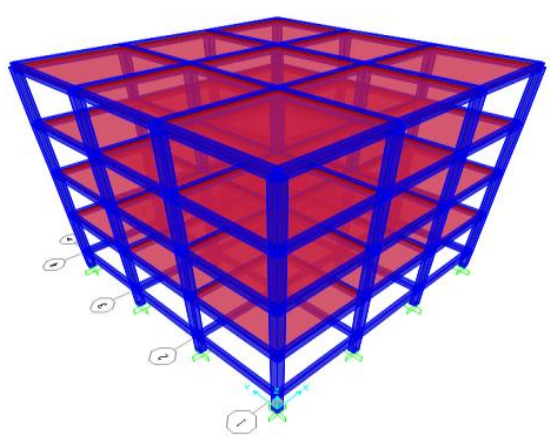

FIG.1: 3D view of RCC Building

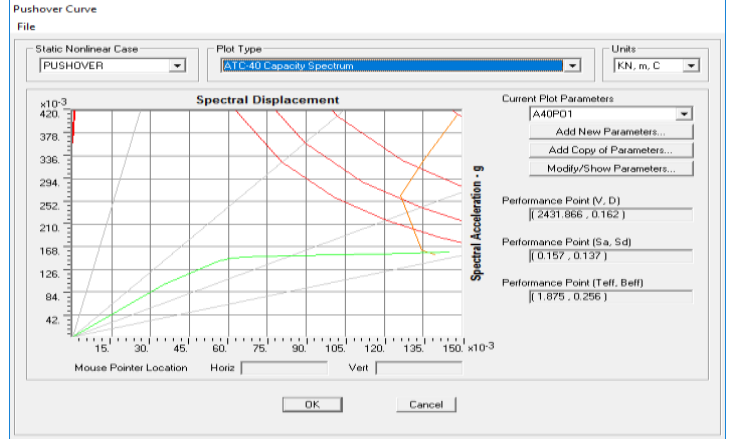

FIG.2: Performance Point $(\mathrm{R}=5)$

Figure 1 shows 3D view of RCC building with bare frame. The capacity spectrum curve obtained from nonlinear static analysis is shown in Figure 2. The ultimate lateral load carrying capacity of building at performance point is around $2431.86 \mathrm{kN}$ and the corresponding roof displacement is $162 \mathrm{~mm}$.

\begin{tabular}{|c|c|c|c|c|c|c|c|c|c|}
\hline Step & Displacemer & Basefocce & $A 10 B$ & Btolo & 10tols & LStoCP & CPtoC & $\mathrm{Clol}_{\mathrm{S}}$ & \\
\hline & $\mathrm{m}$ & $\mathrm{KN}$ & & & & & & & \\
\hline & 0 9.546E-17 & 0.000 & 400 & 0 & 0 & & & 5] & 0 \\
\hline & \begin{tabular}{l|l|} 
& 0.043831 \\
\end{tabular} & 1388.243 & 399 & 1 & 0 & & & 0 & n \\
\hline & \begin{tabular}{|l|l|}
2 & 0.070283 \\
\end{tabular} & 2042.103 & 350 & 50 & 0 & & & f) & 0 \\
\hline & \begin{tabular}{|l|l|}
3 & 0.076959
\end{tabular} & 2136.019 & 325 & 75 & 0 & & & 5. & 0 \\
\hline & \begin{tabular}{l|l|l|}
4 & 0.099000 \\
\end{tabular} & 2206.164 & 304 & 96 & 0 & & & f) & 0 \\
\hline & 5 & 2409.676 & 280 & 64 & 41 & & & t) & 0 \\
\hline & \begin{tabular}{|c|c|c|c|c|}
6 \\
\end{tabular} & 2460.083 & 273 & 69 & 14 & & & of & 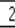 \\
\hline
\end{tabular}

FIG.3: Hinges of Performance Levels (CASE-1)

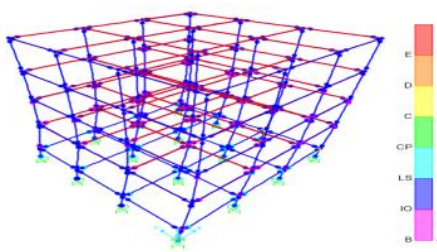

FIG.4: Deflected Shape of Building

At performance point, out of 400 assigned hinges, 273 hinges were in linear range, 69 were in B - IO (Immediate occupancy) range, 14 were in IO - LS (Life safety) range, 42 were in LS - CP (Collapse Prevention) and 2 were in C - D (Collapse). Thus the overall building performance is considered to be in Collapse.

\section{II. $\quad$ RCC Building with Bare Frame $(\mathrm{R}=3)$}

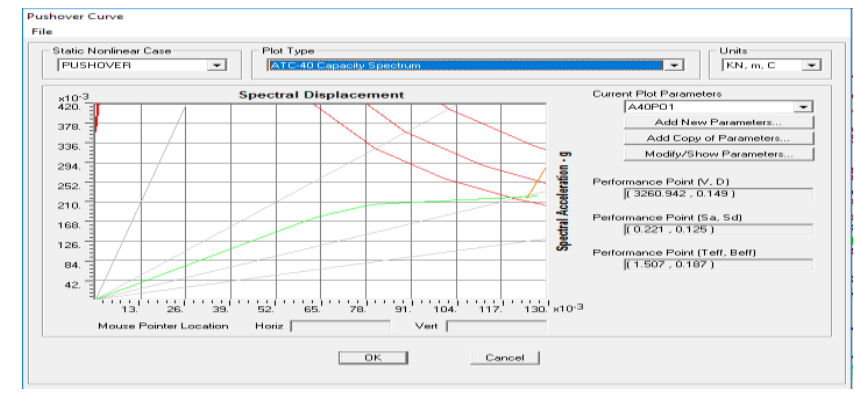

FIG.5: Performance Point ( $\mathrm{R}=3)$ 


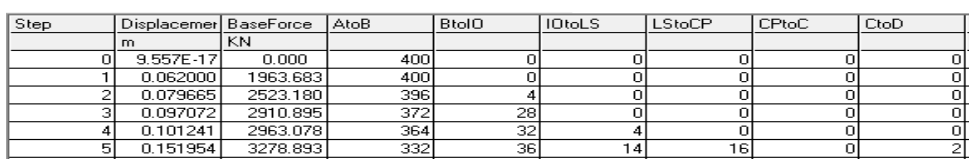

FIG.6: Hinges of Performance Levels (CASE-2)

At performance point, the ultimate load carrying capacity of building is $3260.94 \mathrm{kN}$ and the corresponding roof displacement is $149 \mathrm{~mm}$. And it is observed that, out of 400 assigned hinges, 332 hinges were in linear range, 36 were in B - IO (Immediate occupancy) range, 14 were in IO - LS (Life safety) range, 16 were in LS - CP (Collapse Prevention) and 2 were in $\mathrm{C}-\mathrm{D}$ (Collapse). Thus, the overall building performance is considered to be in Collapse.

By comparing both the cases $1 \& 2$, it is observed that, there 2 hinges of both the cases are in Collapse level but if that will be recovered by changing the design of that particular member then both the cases will comes in Collapse Prevention Level. As observed, performance of model having response reduction factor 3 is more preferable than model having response reduction factor 5, because Lateral Load Carrying Capacity increases thus Displacement decreases and also hinges at collapse prevention level is more in case 1.

\section{RCC Building with Shear Wall $(\mathrm{R}=5)$}

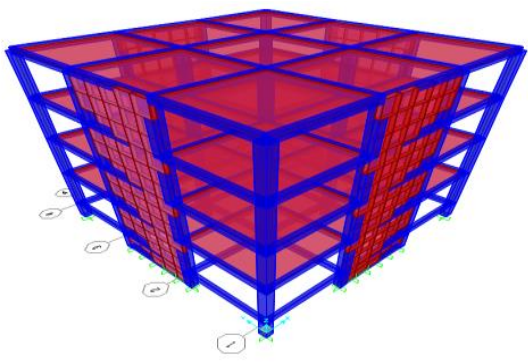

FIG.7: 3D view of RCC Building with Shear Wall

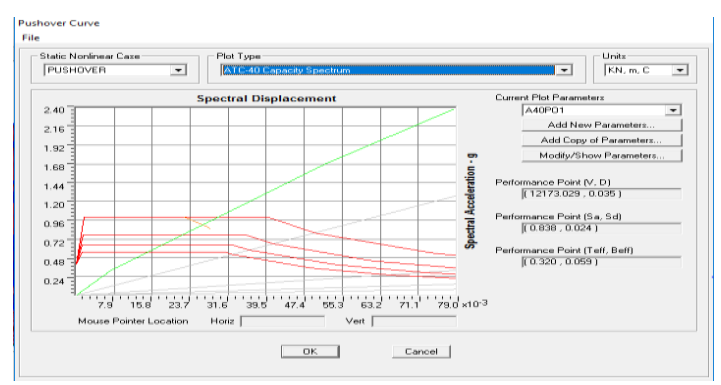

FIG.8: Performance Point $(\mathrm{R}=5)$

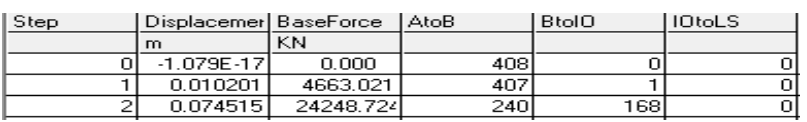

FIG.9: Hinges of Performance Levels (CASE-3)

At performance point, lateral load carrying capacity of structure is $12173.029 \mathrm{kN}$ with a displacement of $35 \mathrm{~mm}$ and also have developed 168 hinges in immediate occupancy level.

\section{RCC Building with Shear Wall $(\mathrm{R}=3)$}

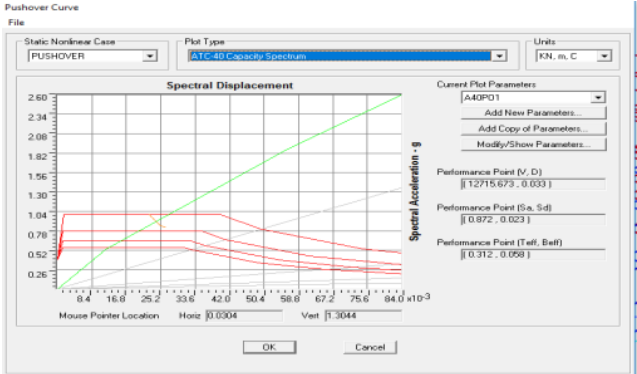

FIG.10: Performance Point ( $\mathrm{R}=3$ )

\begin{tabular}{|c|c|c|c|c|c|}
\hline Step & Displacemer & Baseforce & AtoB & Btol0 & IOtoLS \\
\hline & $\mathrm{m}$ & $\mathrm{KN}$ & & & \\
\hline 0 & \begin{tabular}{|l|l|}
$-1.079 E-17$ \\
\end{tabular} & 0.000 & 400 & 0 & 4 \\
\hline 1 & 0.017166 & 7846.898 & 407 & 1 & 0 \\
\hline 2 & 0.080748 & 27108.645 & 229 & 175 & 4 \\
\hline
\end{tabular}

FIG.11: Hinges of Performance Levels (CASE-4) 
At performance point, lateral load carrying capacity of structure is $12175.673 \mathrm{kN}$ with a displacement of $33 \mathrm{~mm}$ and also have developed 175 hinges in immediate occupancy level and 4 hinges in life safety.

By comparing cases $3 \& 4$, there were not much difference observed in lateral load carrying capacity and displacement, but it is observed that, Performance of case 3 is more preferable than case 4 because case 4 is in life safety level while case 3 is in immediate occupancy.

\section{V. $\quad$ RCC with Stiffness Asymmetry $(\mathrm{R}=5)$}

For stiffness asymmetry in cases 5 and 6, as per IS 1893 (part 1): 2002

$$
\mathrm{K}_{\mathrm{i}}<0.7 \mathrm{~K}_{\mathrm{i}+1}
$$

For that, no shear walls are provided at ground and first floor and at second and third floor, four shear walls are provided of $5 \mathrm{~m}$ length and $200 \mathrm{~mm}$ thickness.

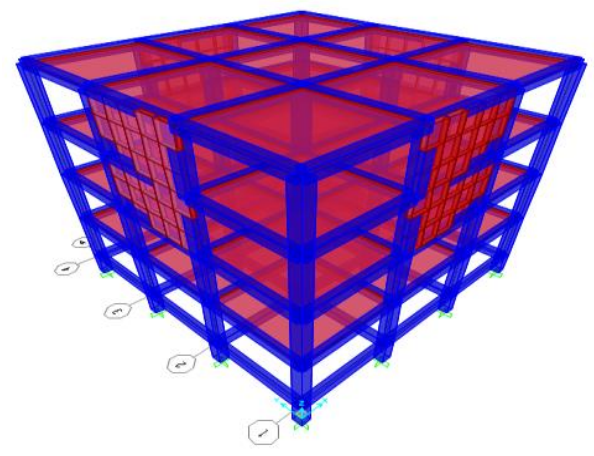

FIG.12: 3D view of RCC Building with Stiffness Asymmetry

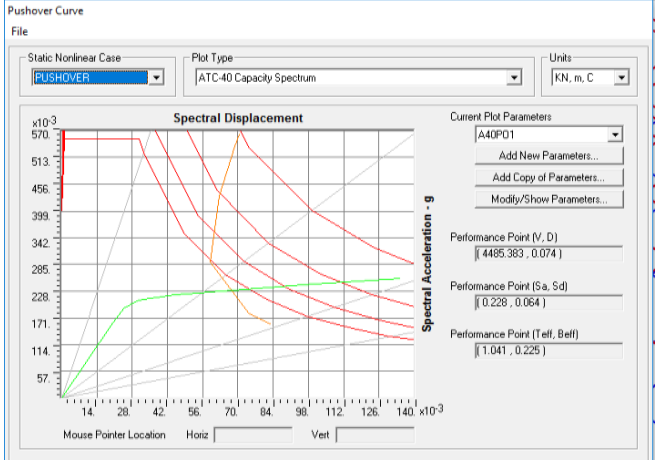

FIG.13: Performance Point (R=5)

At performance point, lateral load carrying capacity of structure is $4485.383 \mathrm{kN}$ with a displacement of $74 \mathrm{~mm}$ and also have developed 84 hinges in immediate occupancy and 55 hinges in life safety.

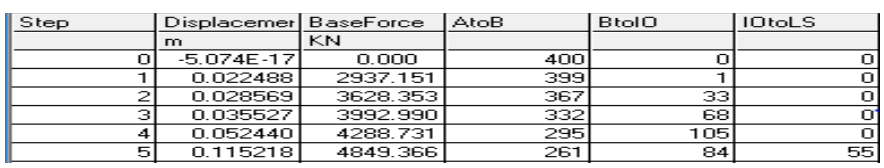

FIG.14: Hinges of Performance Levels (CASE-5)

\section{RCC with Stiffness Asymmetry $(\mathrm{R}=3)$}

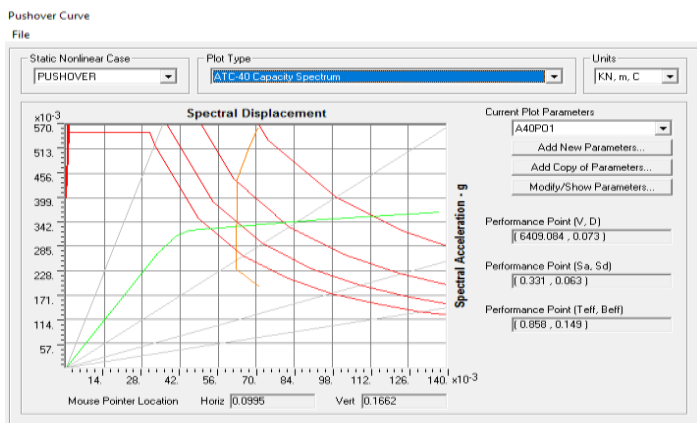

FIG.15: Performance Point (R=3)

\begin{tabular}{|c|c|c|c|c|c|c|}
\hline Step & Displacemer & Baseforce & $A 10 B$ & Btol & & Otols \\
\hline & $\mathrm{m}$ & KN & & & & \\
\hline & $0.5075 E \cdot 17$ & 0.000 & 400 & & 0 & \\
\hline & 0.0389949 & 5087.207 & 398 & & 2 & \\
\hline & \begin{tabular}{l|l}
2 & 0.047008
\end{tabular} & 5869.791 & 356 & & $\overline{42}$ & \\
\hline & 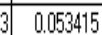 & 6150.298 & 33 & & 69 & \\
\hline & $\begin{array}{lll}4 & 0.108342\end{array}$ & 6878.782 & 288 & & 64 & \\
\hline
\end{tabular}

FIG.16: Hinges of Performance Levels (CASE-6) 
At performance point, lateral load carrying capacity of structure is $6409.084 \mathrm{kN}$ with a displacement of $73 \mathrm{~mm}$ and also have developed 64 hinges in immediate occupancy level and 50 hinges in life safety.

By comparing cases $5 \& 6$, it is observed that there is not much difference in hinges and displacement in structure. According to the result it is drawn that model 6 is preferable because of having more lateral load carrying capacity then case 5 .

By comparing cases $3 \& 5$, it is observed that lateral load carrying capacity decreases highly in stiffness asymmetry and hinges increases because the performance level of the case 5 is life safety while performance level of case 3 is immediate occupancy.

\section{CONCLUSIONS}

Based on the analysis carried out in the present study, the following conclusions can be drawn:

- The seismic performance level as well as the hinge formation significantly depends on the response reduction factor.

- The lateral load resisting capacity of the building increases with the decrease in response reduction factor.

The building with stiffness asymmetry suffers more damage and more number of hinges towards collapse level as compared to the building with full shear wall.

\section{REFERENCES}

A. Jose A. SY., Naveed Anwar, Thaung Htitaung and Deepak Rayamajhi, Performance based seismic design state of practice, 2012, Manila, Philippines. International Journal of HighRise Buildings.

B. FEMA 356 NEHRP pre standard and commentary for the seismic rehabilitation of buildings. (2000).

C. ATC Seismic Evaluation and retrofit of concrete buildings- volume 1 (ATC40). Report no. SSC 96-01. Redwood City (CA): Applied Technology Council; 1996.

D. IS 1893 - 2002 (Part-1), Criteria for earthquake resistance design of structure. Bureau of Indian standard, 2002.

E. IS 456: 2000, Plain and Reinforced Concrete - Code of Practice. Bureau of Indian Standard.

F. Suchita Hirde, Irshad Mullani, Performance based seismic design of RCC building, International Journal of Engineering Research, 2016.

G. Jenish M. Mistry, Chintan Khatri, Anuj K. Chandiwala, A review on performance based design of Multistory Building, International Journal of Advance Engineering and Research Development, 2015.

H. Rajkumar Dubal, Gole Neha, Patil G. R., Sandip Vasanwala, Chetan Modhera, Application ofpreformance based seismic design mothod to reinforced concrete moment resistant frame with vertical geometric irregularity with soft storey, American Journal of Engineering Research, 2014. 